\title{
Correction to: Fluoxetine and Riluzole Mitigates Manganese-Induced Disruption of Glutamate Transporters and Excitotoxicity via Ephrin-A3/GLAST-GLT-1/Glu Signaling Pathway in Striatum of Mice
}

Zhipeng $\mathrm{Qi}^{1} \cdot$ Xinxin Yang ${ }^{1} \cdot$ Yanqi Sang ${ }^{1} \cdot$ Yanan Liu ${ }^{1} \cdot$ Jiashuo $\mathrm{Li}^{1} \cdot$ Bin $\mathrm{Xu}^{1} \cdot$ Wei Liu ${ }^{1} \cdot$ Miao He ${ }^{1} \cdot \mathrm{Zhaofa} \mathrm{Xu}^{1}$. Yu Deng ${ }^{1} \cdot$ Jinghai Zhu ${ }^{1}$

Published online: 14 September 2020

(C) Springer Science+Business Media, LLC, part of Springer Nature 2020

Correction to: Neurotoxicity Research (2020) 38:508-523 https://doi.org/10.1007/s12640-020-00209-w

The original article contains mistake. Figure $3 \mathrm{~d}$ and Figure $3 \mathrm{e}$ were repeated. Correct Fig. 3d is shown below

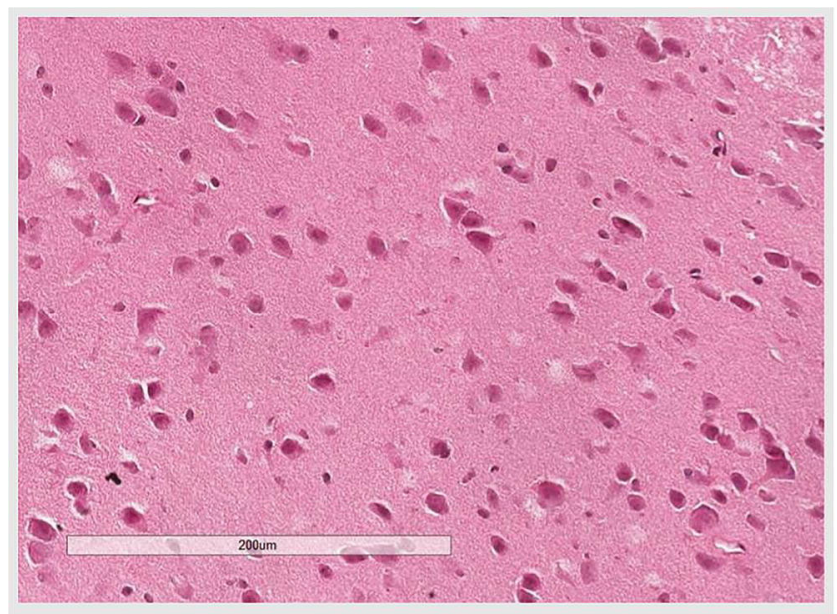

Publisher's Note Springer Nature remains neutral with regard to jurisdictional claims in published maps and institutional affiliations.

The online version of the original article can be found at https://doi.org/ 10.1007/s12640-020-00209-w

Yu Deng

dengyu.cmu@163.com

$\triangle$ Jinghai Zhu

zhujinghai_cmu@163.com

1 Department of Environmental Health, School of Public Health, China Medical University, No.77 Puhe Road, Shenyang North New Area, Shenyang 110122, Liaoning, People's Republic of China 